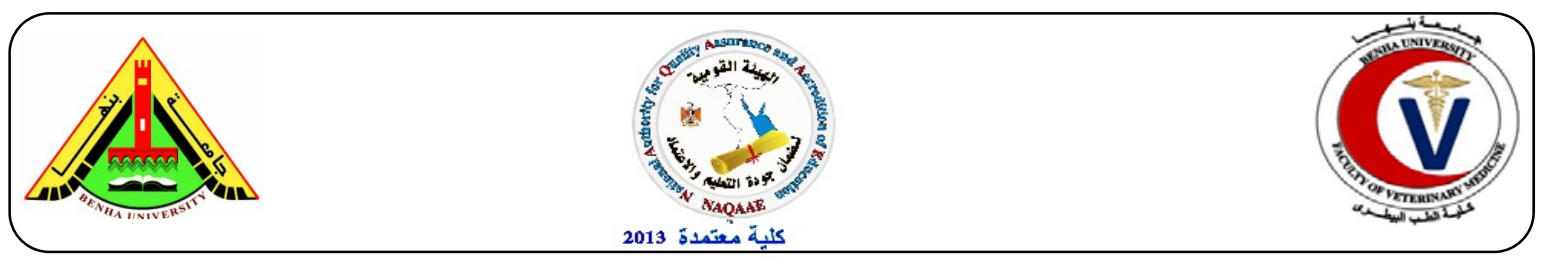

\title{
Persistence of deltamethrin and diazinon in environment of dairy farm
}

\author{
Marzouk, M.A. ${ }^{1}$, Ashoub, M.M.A. ${ }^{1}$, Metawea, Y.F. ${ }^{1}$, Mansour, A.H. ${ }^{2}$, Azam A.E.S. ${ }^{1}$ \\ ${ }^{1}$ Department of Animal, Poultry and Environmental Hygiene, Faculty of Veterinary Medicine, Benha \\ University. ${ }^{2}$ Department of Food Hygiene in Biotechnology, Animal Health Research Institute, Dokki, \\ Cairo, Egypt
}

\section{A B S T R A C T}

The present study was carried out to investigate the persistence of some pesticides (diazinon and deltamethrin) in water, feeds and milk. The obtained results illustrated that diazinonwas persisted for longer time in water, feed and milk samples than deltamethrin, it disappears within $21^{\text {st }}$ and $14^{\text {th }}$ day after application in water and feed, respectively, while it disappears within $30^{\text {th }}$ day after application in milk. Moreover, deltamethrin disappear within $7^{\text {th }}$ day after application in feed and water, while in milk it disappears within $21^{\text {st }}$ day after application. We concluded that diazinon and deltamethrin were persisted in milk for longer time than both feed and water. Pesticides contamination of milk and milk products may lead to acute or chronic toxicity for human being representing public health hazards through their cumulative effects.

Keywords: Diazinon, Deltamethrin, Persistence, Milk.

(BVMJ-30(1): 254-259, 2016)

\section{INTRODUCTION}

$\mathrm{E}$ gypt is one of the largest users of pesticides in order to duplicate her animal and plant production power. Several pesticides contain noxious substances that persist in the environment for a long time. Pesticide residues may be resulted in environmental contamination as well as human health hazards (Latif et al., 2011). About 8.5 million $\mathrm{kg}$ of pesticides are used in non-agricultural uses, as livestock and pet insect, grain storage and turf protection that based on their low cost, broad spectrum effectiveness and multi-pest control capability (US EPA, 2002). Some pesticides are biodegradable, while others persist in the soils for longer times (Tariq et al., 2006). Pesticide residues have been detected in the vegetables and cereals (Parveen et al., 2005), and in various water sources (Saqib et al., 2005). In order to avoid the toxic health hazards, it is necessary to determine the levels of pesticides in food of animal origin such as milk especially at spraying areas. Milk contamination by pesticides can also caused by their application to the cow's body, in the cow barns, or even in the milk processing areas (Bogialli et al., 2004). Moreover, the feed to milk transference of pesticides is influenced by quantity ingested, absorption, pesticide metabolism and excretion by animals in production. Thus, the best risk management tool is prevention of exposure, either through feed or from the environment, of the animals to these contaminants, as well as the application of the withdrawal time (Kan\& Meijer, 2007). Detection of pesticide residues in milk of ruminants represents a public health hazard, since milk and dairy products are widely consumed by infants, children and adults throughout the world. In view of this, many countries have enacted regulations to set the permissible limits of such pesticide residues in milk and dairy product to protect the consumers (Tsiplakou et al., 2010). 
This study was carried out to investigate the persistence of some pesticides (diazinon and deltamethrin) in water, feeds and milk.

\section{MATERIAL AND METHODS}

\subsection{Sampling}

Sixty nine water and feed samples were collected (24 of each) at the same day of spraying before and after application for each diazinon and deltamethrin, the amounts of sampling were varied from 0.36- 4.8 L and 120-600 gm for water and feed, respectively according to our need in the methods used for analysis. All the samples were stored throughout the experiment (30 day) at room temperature. Sampling was carried out at different intervals, $1^{\text {st }}, 2^{\text {nd }}, 3^{\text {rd }}, 7^{\text {th }}, 14^{\text {th }}, 21^{\text {st }}$, and $30^{\text {th }}$ after application (invitro). Water samples were collected from drinker in glass bottle, while feed samples (Corn-Drees-SilageSoya-Bran-Linseed-Molasses-Hey-Grille feed- Berseem) collected from feed troughs. Forty-eight fresh milk samples were collected from dairy farm at the same day of spraying before and after application at different intervals as mentioned before (in vivo) in polyethylene bags. The milk analysis was in the same day of collection or kept frozen.

\subsection{Standards}

Standard of diazinon was obtained from $\mathrm{GmbH}$ (Augsburg, Germany), and deltamethrin (97\% to $99 \%)$ was granted by Pak China.

\subsection{Deltamethrin in feed water and milk}

water samples were done with HPLC-UV by chromatograph equipped with UV detector according to Flavio et al., (1999), while for feed samples used HPLC-UV detector according to Boussahel et al., (2006). Deltamethrin detection in milk was conducted on HPLC system using Photodiod array (PDA) detector according to Darko and Acquaah (2008).

\subsection{Diazinon in water, feed and milk}

The procedure of water samples was carried out by using gas chromatography method using flame photometric detector (FPD) according to Martinez Vedail et al ., (2002), while for feeds the protocol of QuEChERS Mini-residue method for the analysis of diazinon concerning commodities with high fat content according to Anastassiades et al., (2003). Because there are a lot of modifications of the QuEChERS method published, the procedure followed is described in detail (QuEChERS, 2009). The detection of diazinon in milk was carried out by GC equipped with an electron capture detector according to Walorczyk (2008).

\subsection{Statistical analysis}

Statistical analysis of data was carried out using the SPSS Microsoft version 16.0.1. One-way ANOVA tests to check the significant difference (SPSS, 2004).

\section{RESULTS}

The obtained results in the tableshowed that the mean values of deltamethrin in water samples were $54.00 \pm 17.92,30.67 \pm 6.89$ and $9.20 \pm 3.60 \mu \mathrm{g} / \mathrm{L}$, respectively in the ${ }^{\text {st }}, 2^{\text {nd }}$ and $3^{\text {rd }}$ day after application, while the mean values of diazinon were $77.00 \pm 25.56$, $73.91 \pm 24.70,18.73 \pm 6.73,6.20 \pm 2.61$ and $1.20 \pm 0.40 \mu \mathrm{g} / \mathrm{L}$, respectively in the $1^{\text {st }}, 2^{\text {nd }}$, $3^{\text {rd }}, 7^{\text {th }}$ and $14^{\text {th }}$ day after application. It is clear from the table that the mean values of deltamethrin in feed samples were $80.00 \pm 26.57,44.23 \pm 14.39$ and $10.20 \pm 3.30$ $\mu \mathrm{g} / \mathrm{kg}$, respectively in the $1^{\text {st }}, 2^{\text {nd }}$ and $3^{\text {rd }}$ day after application, while the mean values of diazinon were $84.51 \pm 28.91,45.63 \pm 14.57$, $17.33 \pm 5.33$ and $3.66 \pm 1.65 \mu \mathrm{g} / \mathrm{kg}$, respectively in the $1^{\text {st }}, 2^{\text {nd }}, 3^{\text {rd }}$ and $7^{\text {th }}$ day after application. The obtained results illustrated in the table showed that the mean values of deltamethrin in milk samples were $25.40 \pm 8.13,13.47 \pm 44.13,7.48 \pm 2.19$ and $0.32 \pm 0.10 \mu \mathrm{g} / \mathrm{kg}$, respectively in the $1^{\text {st }}$, $2^{\text {nd }}, 3^{\text {rd }}$ and $7^{\text {th }}$ day after application, while the mean values of diazinon were 55.97 $\pm 18.36,45.07 \pm 15.36,25.7 \pm 8.36$, 
Table (1) The persistence of deltamethrin and diazinon in water, feed and milk in different dairy farms $(n=144)$.

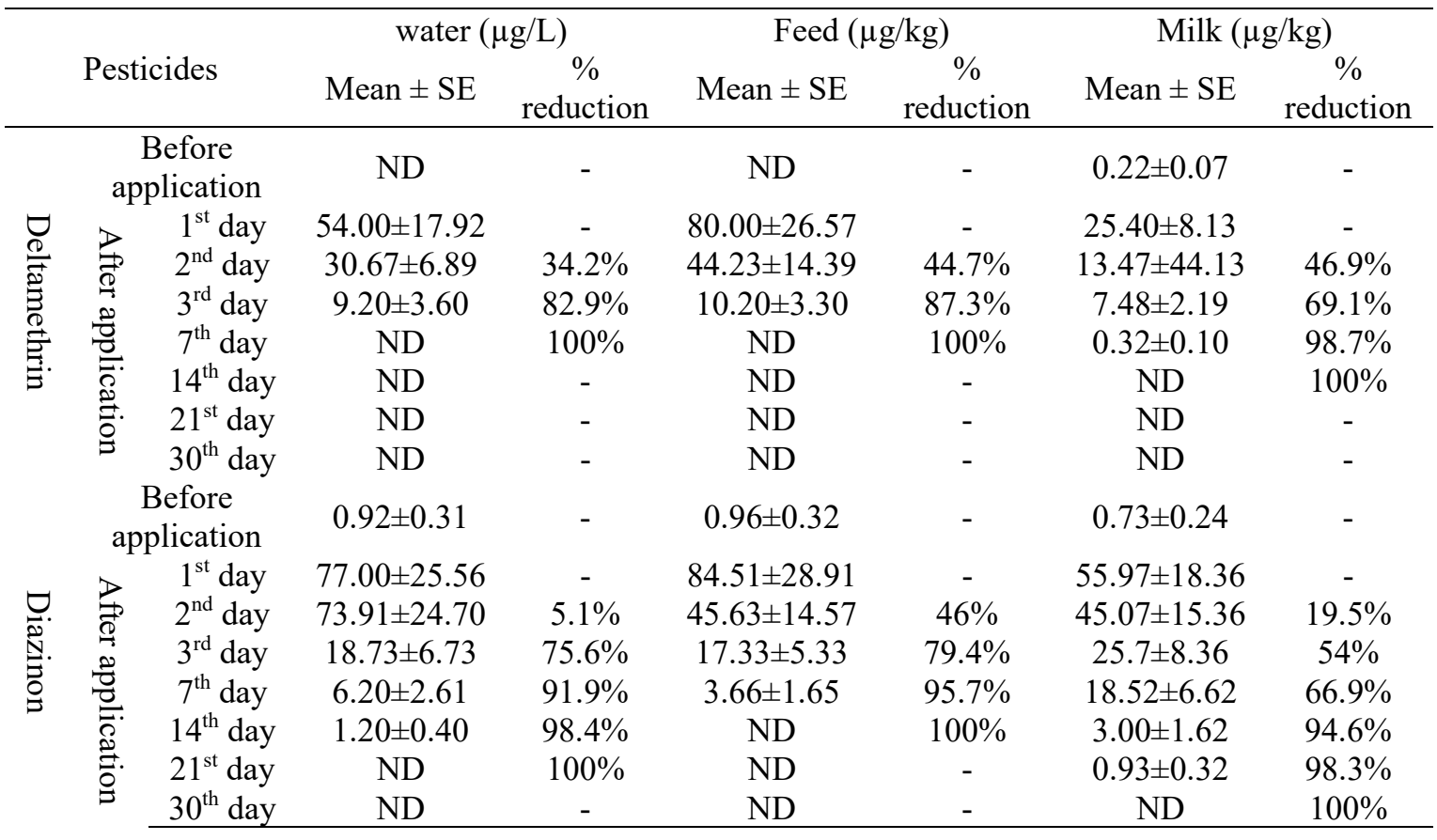

$18.52 \pm 6.62, \quad 3.00 \pm 1.62$ and $0.93 \pm 0.32$ $\mu \mathrm{g} / \mathrm{kg}$, respectively in $1 \mathrm{st}, 2 \mathrm{nd}, 3 \mathrm{rd}, 7 \mathrm{th}$, 14 th and 21 st day after application.

\section{DISCUSSION}

The results in the table showed that spraying process of deltamethrin cause contamination of drinking water and drinkers in a level higher than permissible limit, even after first few days of application and persist for several days but in very minute amounts. Deltamethrin was not detected in water samples within $7^{\text {th }}$ day after application. The current findings agreed quite well, with those recorded by Thomson (1989). Moreover, Goodarzi et al., (2010) mentioned that after the releasing of deltamethrin into water, it adsorbed to suspended solids and sediment based, biodegradation may be expected in aqueous environments. Volatilization from water surfaces is expected to be an important fate process. It is clear from the table that diazinon residue disappeared within $21^{\text {st }}$ day after application. These findings were nearly similar to those obtained by Giddings (1996) and Shayeghi et al., (2001) who reported that rivers are contaminated with OP pesticideresidues (diazinon). Moreover, it persisted in environment at higher concentration than the allowable limits for 1 month after the spraying. Concerning to feed samples, the results clarified that during deltamethrin application in modern dairy farms, to eliminate ectoparasites on animals, it also caused contamination of feedstuff in feed troughs and storage room. Deltamethrin residues were not detected in feed samples within $7^{\text {th }}$ day after application. The current findings agreed quite well, with those recorded by Haug and Hoffman (1990). On the other hand, Yu C et al., (2014) reported that the half-life of deltamethrin were 23-24 days on stored feeds in clean, dry and cooled area which not exposed to environmental factors. It is clear from the table that diazinon was not detected in feed samples collected at $14^{\text {th }}$ 
day after application. The obtained results came in accordance with those recorded by Currie et al., (1990), Tavakol (2007) and Arjmandi et al., (2010) who said that the highest level of diazinon was detected one day after the spraying of agriculture station in amount of $1.14 \mathrm{ppm}$, while at $1^{\text {st }}$ and $2^{\text {nd }}$ week after application the levels were decreased to 0.6636 and $0.048 \mathrm{ppm}$, respectively. Also, the amount of diazinon was not detected after one and two months after the spraying. On the other hand, Bondarenko and Gan (2004) found that the amounts of diazinon were detectable until the first month after the spraying phase. This may be attributed to high persistency of diazinon in the ambient environment. While, Beaton et al., (2010) mentioned that accidents during filling spray equipment often result in contamination that are hazardous to human and livestock health. Residues can be up to 500 times higher than concentration caused from spray drift or indirect contamination. Moreover, Currie et al., (1990) reported that diazinon is more persistent than other OP pesticides as it precipitated onto the floors, surface, drinkers and water troughs $4 \mathrm{hr}$ (peaks) after application and lasted for 10 days. Concerning to milk samples, the results showed that deltamethrin descend in milk for several days after spraying not only from consumption of contaminated water and feed, but also from lack of precautions and absence of awareness. The residue of sprayed deltamethrin disappeared within $21^{\text {st }}$ day after application. The current findings agreed quite well, with those recorded by Kan and Meijer (2007) and Yu $\mathrm{C}$ et al., (2014). The current findings disagreed quite well, with those recorded by Akhtar et al., (1992) who found that the levels of deltamethrin were $0.0095,0.011$, $0.0065,0.0135,0.002$ and $0.01 \mathrm{mg} / \mathrm{kg}$ in milk samples collected in the $4^{\text {th }}, 10^{\text {th }}$, $11^{\text {th }}, 18^{\text {th }}, 25^{\text {th }}$ and $28^{\text {th }}$ day respectively, from treated cows subcutaneously with $2 \mathrm{ppm}$ deltamethrin $(2000 \mu \mathrm{g} / \mathrm{kg})$.

The variation in persistence of pesticides may be attributed to type and concentration of pesticides, source of feed and water as well as mode of pesticide application (Turi et al., 2000). It is clear from the table that diazinon residue was not detected in milk samples within $30^{\text {th }}$ day after application. The obtained results came in accordance with those recorded by Kabir et al., (2008). Moreover, Meister (2000) found that diazinon may be stored in fats for two weeks, while application of diazinon to the skin may be resulted in passing residues to milk 24 hours after application. Our results concluded that diazinon was persisted in water, feed and milk for longer time than deltamethrin. However, deltamethrin rapid degradable pesticides, it may contaminate large number of collected samples that may be attributed to application without any precaution and without following the instructions and dose on the bottle during application. Moreover, both diazinon and deltamethrin were persisted in milk for longer time than in water and feed, this may be attributed to store in lipid inside dairy cows and excreted in milk according to fat $\%$, milk yield and times of milking/day ( $\mathrm{Yu}$ et al., 2014).

From all of these, several precautions should be taken during pesticides application to minimize reaching of residues to animal body and milk which may contribute to public health hazards especially for children.

\section{REFERENCES}

Akhtar, M.H., Danis, C., Trenholm, H.L., Hartin, K.E. 1992. Deltamethrin residues in milk and tissues of lactating dairy cows. J. Environ. Sci. Health, Part B 27 (3): 235-253.

Anastassiades, M., Lehotay, S.J., Štajnbaher, D., Schenck, F.J. 2003. Fast and easy multiresidue method employing acetonitrile extraction/partitioning and "dispersive solid-phase extraction" for the determination of pesticide residues in produce, Journal of AOAC International, 86(2): 412-431. 
Arjmandi, R., Tavakol, M., Shayeghi, M. 2010.Determination of organophosphorus insecticide residues in the rice paddies.Int. J. Environ. Sci. Tech, 7 (1): 175-182.

Beaton, D., Jamieson, A., Eng, P. 2010. Pesticide Contamination of Farm Water Supplies Recommendations on Avoidance, Clean-up and Responsibilities. Agricultural Information Contact Centre: 1-877424-1300.Northern Ontario Regional Office: 1-800-461-6132 E-mail: ag.info.omafra@ontario.ca.

Bogialli, S., Curini, R., Di Cortia, A., Laganà, A., Nazzari.M., Tonci, M. 2004.Methods. J. Chromatogr., 21(3):461-468.

Bondarenko, S., Gan, J.Y. 2004.Degradation and sorption of selected organophosphate and carbamate insecticides in urban stream sediments. Environmental Toxicology and Chemistry, 23:18091814.

Boussahel, R., Moussaoui, K.M., Harik, D. 2006. Determination of residues of deltamethrin in wheat and potato by HPLC. African Journal of Agricultural Research, 1(5):182-185. http://www.academicjournals.org/AJ AR

Currie, K. L., McDonald, E.C., Chung, L.T.K., Higgs, A.R. 1990.Concentrations of diazinon, chlorpyrifos, and bendiocarb after application in office. Am Ind Hyg Assoc, 51: 23-27.

Darko, G., Acquaah, S.O. 2008. Level of organochlorine pesticides residues in dairy products in Kumasi, Ghana. Chemosphere, 71 (1): 294-298.

Fagnani, F., Beloti, V., Paula, A., Battaglini, P., Karen, S. Dunga, Tamanini, R. 2011. Organophosphorus and carbamates residues in milk and feedstuff supplied to dairy cattle, Pesq. Vet. Bras. 31(7):598-602.
Flavio, A.P., Rogerio, M.D., Renato, Z., Ayrton, F.M. 1999. Determination of Deltamethrin in Cattle Dipping Baths by High-Performance Liquid Chromatography. J. Agric. Food Chem., 47(1): 174-176.

Giddings, J.M., Biever, R.C.; Annunziato, M.F., Hosmer, A. J. 1996.Effects of diazinon on large outdoor pond microcosms. Environmental Toxicology and Chemistry, 15(5): 618-629.

Goodarzi, M., Ortiz, E.V., Coelho, L.S., Duchowicz, P.R. 2010. Linear and non-linear relationships mapping the Henry's law parameters of organic pesticides. Atmos Environ, 44: 31793186.

Haug, G., Hoffman, H. 1990. Chemistry of Plant Protection 4: Synthetic Pyrethroid Insecticides: Structures and Properties. Springer-Verlag. Berlin, Heidelberg, New York.

Kabir, K.H., Rahman, M.A., Ahmed, M.S., Prodhan, M.D.H., Akon, M.W. 2008 Determination of residue of diazinon and carbosulfan in brinjal and quinalphos in yard long bean under supervised field trial. Bangladesh J. Agril., Res. 33(3): 503-513.

Kan, C.A., Meijer, G.A.L. 2007. The risk of contamination of food with toxic substances present in animal feed. Animal Feed Science and Technology, 133 (2007): 84-108.

Latif, Y., Sherazi, S.T.H., Bhanger, M.I. 2011.Monitoring of pesticide residues in commonly used Fruits in Hyderabad Region, Pakistan. American Journal of Analytical Chemistry, 2 (8A): 46-52.

Martinez Vidal, J.L. 2002. Estimation and correction of matrix effects in gas chromatographic pesticide multiresidue analytical methods with a nitrogen phosphorus detector, The Analyst, 127(8): 1038-1044.

Meister, R. 2000. Farm Chemicals Handbook. Meister Publishing Company, Willoughby, $\mathrm{OH}$. 
Parveen, Z., Khuhro, M.I., Rafiq, N. 2005. Monitoring of pesticide residues in vegetables (2000- 2003) in Karachi, Pakistan. Bull Environ ContamToxicol, 74: 170-176.

QuEChERS2009.A Mini-Multiresidue Method for the Analysis of Pesticide Residues in Low-Fat Products.http://www. quechers.com

Saqib, T.A., Naqvi, S.N., Siddiqui, P.A., Azmi, M.A. 2005. Detection of pesticide residues in muscles, liver and fat of 3 species of Labeo found in Kalri and Haleji lakes. J Environ Biol, 26: 433-438.

Shayeghi, M., Shahtaheri, S.J., Selseleh, M. 2001. Phosphorous insecticides residues in Mazandaran River Waters, Iran, Iran. J. Public Health. 30 (1): $115-118$

SPSS 2004.statistical package for social science. Release 16.0.1 version. SPSS Inc

Tariq, M.I., Afzal, S., Hussain, I. 2006. Degradation and persistence of cotton pesticides in sandy loam soils from Punjab, Pakistan. Environ Res, 100: 184-196.

Tavakol, M. 2007.Environmental impact assessment of diazinon in rice fields (a Case Study on Amol Township Rice Fields), M.Sc. Thesis, Science and Research Branch, Islamic Azad University, Tehran, Iran.

Thomson, W.T. 1989.Agricultural Chemicals. Book I: Insecticides. Thomson Publications, Fresno, CA.

Tsiplakou, E., Anagnostopoulos, C.J., Liapis, K., Haroutounian, S.A., Zervas, G. 2010. Pesticides residues in milks and feedstuff of farm animals drawn from Greece. Chemosphere. 80(7): 504 - 512.

Turi, M.S.; Sods, K., Vegh, E. 2000. Determination of residues of pyrethroid and organophosphorus ectoparasiticides in foods of animal origin. Acta. Vet. Hung. 48(2): 139149.
Us EPA 2002. Revised Organophosphorous Pesticide Cumulative Risk Assessment.US Environmental Protection Agency Office of Pesticide Programs, Washington, DC.http://www.epa.gov/ pesticides/cumulative/rra-op/ Available.

Vanderford, B. J., Mawhinney, D. B., Trenholm, R.A., Zeigler-Holady, J.C., Snyder, S.A. 2011. Assessment of sample preservation techniques for pharmaceuticals, personal care products, and steroids in surface and drinking water. Anal Bioanal. Chem. 399(6):2227 - 2234.

Walorczyk, S. 2008. Development of a multi-residue method for the determination of pesticides in cereals and dry animal feed using gas chromatography-tandem quadrupole mass spectrometry II. Improvement and extension to new analytes. J. Chromatogr. A 1208: 202-214.

Yu, C.,Li, Y.,Zhang, Q.,Zou, N.,Gu, K.,Li, X., Pan, C. 2014. Decrease of pirimiphos-methyl and deltamethrin residues in stored rice with post-harvest treatment. Int $\mathrm{J}$ Environ Res Public Health. 16; 11 (5):5372-81. 